\title{
Exercise capacity and spontaneous heart rhythm after transvenous fulguration of atrioventricular conduction
}

\author{
P M SCHOFIELD, R J BOWES, N BROOKS, D H BENNETT \\ From the Regional Cardiac Centre, Wythenshawe Hospital, Manchester
}

SUMMARY Twenty nine patients who had had refractory supraventricular tachycardia were studied 4-36 (mean 16) months after transvenous fulguration of the atrioventricular junction. Twenty two had complete atrioventricular block, five partial atrioventricular block, and two had atrioventricular conduction via an accessory atrioventricular pathway. Though all patients were free of palpitation after the procedure, exertional dyspnoea had developed in 13 and in two patients pre-existing dyspnoea had worsened. During ventricular demand pacing, exercise time was reduced to $43 \%$ of the predicted value for their age and sex. The 16 patients with rate responsive pacemakers demonstrated a significantly better but still impaired exercise capacity during "physiological" pacing as compared with their performance during constant rate pacing. In patients with complete atrioventricular block there was an increase in spontaneous ventricular rate during exercise in seven patients and in response to the Valsalva manoeuvre in eight patients. This suggests that the intrinsic ventricular pacemaker is influenced by autonomic nervous system activity in some patients.

It is concluded that though transvenous fulguration is successful in controlling tachycardia it may reduce exercise capacity. Most patients remain in complete atrioventricular block after the procedure and, in contrast with the practice as described in early reports, would benefit from "physiological" pacing-though even with this mode exercise capacity is likely to be abnormal.

Transvenous fulguration of atrioventricular conduction is a new technique used to treat recurrent supraventricular tachycardia in patients who do not respond adequately to, or who cannot tolerate, drug treatment and in whom antitachycardia pacing, where applicable, has proved ineffective. ${ }^{1-3}$ Little is known about its long term sequelae, though earlier reports have documented the rhythms produced. ${ }^{4}$ This study was prompted by the frequent complaints of breathlessness and reduced exercise tolerance from patients after transvenous fulguration of atrioventricular conduction. The aims were to assess exercise capacity and spontaneous heart rhythm, including response to exercise and the Valsalva manoeuvre, after atrioventricular fulguration.

Requests for reprints to Dr P M Schofield, Cardiology Area B, Wythenshawe Hospital, Southmoor Road, Wythenshawe, Manchester M23 9LT.

Accepted for publication 30 June 1986

\section{Patients and methods}

We studied 29 patients (aged 19-67, 22 female). All patients had had frequent symptomatic supraventricular tachycardia and were refractory to or intolerant of antiarrhythmic drugs. Three patients had previously had antitachycardia pacemakers implanted that had not been consistently effective in controlling their symptoms. The arrhythmia that they had was atrioventricular reentrant tachycardia in eight patients, atrioventricular nodal reentrant tachycardia in eight, paroxysmal atrial fibrillation in seven (three had mitral valve disease), paroxysmal atrial tachycardia in two (one had mitral valve disease), and chronic atrial fibrillation/flutter in four (three had mitral valve disease). Though seven patients had mitral valve disease, the remaining 22 patients had no evidence of structural heart disease before transvenous atrioventricular fulguration.

Except for one patient transvenous atrioventricular fulguration was performed under general 
anaesthesia by the technique described previously. ${ }^{4}$ In each case, 1-3 DC shocks of 200-400 J (stored) were delivered to the pole producing the largest unipolar His deflection and a clearly defined atrial electrogram. All patients subsequently had a permanent pacemaker implanted.

For this study, patients were admitted to hospital to assess exercise capacity and spontaneous heart rhythm from 4 to 36 (mean 16) months after transvenous fulguration. The patients were fitted with a Holter cassette recording system after admission. In all cases, during ventricular demand pacing the ventricular rate was gradually reduced to the lowest that the patient could comfortably tolerate, but not $<30$ beats/min. In those patients who did not demonstrate a spontaneous heart rhythm the implanted pacemaker was briefly inhibited to determine the escape interval. The patients rested in bed during their admission (usually for about eight hours) with the pacemaker programmed to a low rate to assess any change in spontaneous heart rhythm. The patients performed the Valsalva manoeuvre during continuous electrocardiographic monitoring so that we could assess the response of the spontaneous heart rhythm to changes in autonomic nervous system activity.

Patients' pacemakers were then temporarily programmed to ventricular demand mode at 60 or 70 beats/min for exercise testing. Twenty eight patients performed symptom-limited treadmill exercise testing according to the standard Bruce protocol to assess exercise capacity and the response of the spontaneous heart rhythm to exercise. The remaining patient, who had mitral valve disease, was considered unsuitable for exercise testing because of her poor exercise tolerance. Sixteen patients with "physiological" pacing systems (10 with $P$ wave synchronised and six with TX (ventricular, QT sensing, rate-responsive) systems) who had been in "physiological" mode since the time of fulguration were exercised in a randomised double-blind manner in ventricular demand mode and rate responsive mode, with at least a $30 \mathrm{~min}$ recovery period in between. We analysed group differences by a one way analysis of

Table 1 Clinical details and spontaneous heart rhythm of 29 patients after transvenous fulguration of atrioventricular conduction

\begin{tabular}{|c|c|c|c|c|c|c|c|c|}
\hline $\begin{array}{l}\text { Case } \\
\text { No }\end{array}$ & $\begin{array}{l}\text { Age } \\
(y r)\end{array}$ & Sex & $\begin{array}{l}\text { Primary } \\
\text { arrhythmia }\end{array}$ & $\begin{array}{l}\text { No of } \\
\text { fulguration } \\
\text { sessions }\end{array}$ & $\begin{array}{l}\text { Time since } \\
\text { fulguration } \\
\text { (mnth) }\end{array}$ & $\begin{array}{l}\text { Spontaneous } \\
\text { heart } \\
\text { rhythm }\end{array}$ & $\begin{array}{l}R-R \text { interval } \\
\text { (ms) during } \\
\text { spontaneous } \\
\text { rhythm }\end{array}$ & $\begin{array}{l}\text { Type of } \\
\text { pacemaker }\end{array}$ \\
\hline 1 & 26 & $\mathbf{F}$ & AVRT & 1 & 34 & $\mathrm{~S} / \mathrm{R} 1^{\circ} \mathrm{HB}$ & NA & VVI \\
\hline 2 & 46 & $\mathrm{~F}$ & AVRT & i & 8 & $\mathrm{CHB}$ & 2420 & $\mathbf{T X}$ \\
\hline 3 & 25 & $\mathrm{~F}$ & AVNRT & i & 20 & $\mathrm{CHB}$ & 1392 & DDD \\
\hline 4 & 19 & $\mathrm{~F}$ & AVNRT & 2 & 7 & $\mathrm{CHB}$ & 1450 & DDD \\
\hline 5 & 39 & $\mathrm{~F}$ & AVNRT & 1 & 19 & CHB & 1340 & DDD \\
\hline 6 & 58 & $\mathrm{~F}$ & PAF & i & 20 & $\mathrm{CHB}$ & 1940 & $\mathrm{TX}$ \\
\hline 7 & 37 & F & PAT & i & 36 & $\mathrm{~S} / \mathrm{R} 1^{\circ} \mathrm{HB}$ & NA & VVI \\
\hline 8 & 46 & $\mathbf{M}$ & AVRT & 1 & 18 & S/Rt & NA & VVI \\
\hline 9 & 51 & $\mathrm{~F}$ & PAF & i & 19 & $\mathrm{CHB}$ & $>5140$ & $\mathrm{TX}$ \\
\hline 10 & 33 & $\mathrm{~F}$ & AVRT & 1 & 7 & $\mathrm{CHB}$ & 1310 & DDD \\
\hline 11 & 32 & $\mathrm{~F}$ & AVRT & 1 & 20 & $\mathrm{CHB}$ & $>6720$ & VVI \\
\hline 12 & 57 & $\mathrm{~F}$ & AVNRT & 1 & 13 & $\mathrm{CHB}$ & 1340 & DDD \\
\hline 13 & 47 & $\mathrm{~F}$ & AVRT & 1 & 16 & $\mathrm{CHB}$ & 1320 & DDD \\
\hline 14 & 52 & $\mathrm{~F}$ & AVNRT & $i$ & 23 & $\mathrm{CHB}$ & 1660 & DDD \\
\hline 15 & 20 & $\mathbf{M}$ & AVRT & 1 & 25 & $\mathbf{S} / \mathbf{R} \ddagger$ & NA & VVI \\
\hline $16^{\star}$ & 66 & $F$ & PAF & $i$ & 7 & CHB & 2480 & VVI \\
\hline 17 & 60 & F & AVNRT & 2 & 16 & $\mathrm{~S} / \mathrm{R} 2^{\circ} \mathrm{HB}$ & NA & DDD \\
\hline 18 & 32 & F & AVNRT & 1 & 31 & $\mathbf{S} / \mathbf{R}$ & NA & DDD \\
\hline $19^{\star}$ & 65 & $\mathbf{F}$ & ChAF & 1 & 13 & СНB & $>4840$ & VVI \\
\hline 20 & 55 & $\mathbf{M}$ & PAF & 1 & 15 & CHB & 1210 & VVT \\
\hline $21 \dagger$ & 67 & M & PAT & 2 & 18 & $\mathrm{CHB}$ & 1300 & VVI \\
\hline $22 \dagger$ & 61 & $\mathbf{F}$ & PAF & 2 & 15 & $\mathrm{CHB}$ & $>4800$ & VVI \\
\hline 23 & 63 & $\mathbf{F}$ & ChAF/ChAFL & 1 & 4 & A flutter & NA & $\mathrm{TX}$ \\
\hline 24 & 30 & $\mathbf{F}$ & AVRT & 1 & 4 & $\mathrm{CHB}$ & 1180 & DDD \\
\hline 25 & 61 & $\mathbf{M}$ & PAF & $i$ & 6 & $\mathrm{CHB}$ & 1480 & $\mathrm{TX}$ \\
\hline $26^{\star}$ & 48 & $\mathbf{M}$ & PAF & 1 & 4 & $\mathrm{CHB}$ & 1960 & $\mathrm{TX}$ \\
\hline $27^{\star}$ & 60 & $\mathbf{F}$ & ChAF & 1 & 6 & $\mathrm{CHB}$ & 1460 & VVI \\
\hline $28^{\star}$ & 63 & $\mathbf{F}$ & ChAF & 1 & 9 & $\mathrm{CHB}$ & 1600 & VVI \\
\hline 29 & 53 & $\mathbf{F}$ & AVNRT & $i$ & 26 & CHB & 1140 & VAT \\
\hline
\end{tabular}

^Mitral valve replacement. †Mitral stenosis. †Conduction via accessory pathway. A flutter, atrial flutter; AVRT, atrioventricular tachycardia; AVNRT, atrioventricular nodal tachycardia; ChAF, chronic atrial fibrillation; ChAFL, chronic atrial flutter; CHB, complete heart block; DDD, dual chamber pacemaker; NA, not applicable; PAF, paroxysmal atrial fibrillation; PAT, paroxysmal atrial tachycardia; S/R, sinus rhythm; S/R $1^{\circ} \mathbf{H B}$, sinus rhythm with first degree heart block; S/R $2^{\circ} \mathrm{HB}$, sinus rhythm with second degree heart block; TX, ventricular, QTsensing pacemaker; VAT, ventricular paced, atrial sensed pacemaker; VVI/VVT, ventricular demand pacemaker. 
variance and by a two way analysis of variance for repeated measures on one factor (mode of pacing). We compared proportions by the $\chi^{2}$ test.

\section{Results}

\section{SPONTANEOUS HEART RHYTHM}

Table 1 shows the clinical details and spontaneous heart rhythm at the time of this study. Twenty two patients had complete atrioventricular block, four had sinus rhythm (conducted with first degree atrioventricular block in two and with second degree block in one), two had 1:1 atrioventricular conduction maintained via an accessory atrioventricular pathway, and one had atrial flutter with 5:1 atrioventricular conduction.

Immediately after fulguration all patients had remained in complete atrioventricular block for at least 24 hours, apart from patient 8 in whom conduction was maintained via a bundle of Kent. Subsequently, four patients had required repeat fulguration because of a return of atrioventricular conduction, which had occurred within the first week in three. Of the five patients who had evidence of atrioventricular conduction at the time of this study, conduction had returned within the first month in only two. Atrioventricular conduction did not return in any patient 6 months after fulguration. Although patient 21 developed first degree atrioventricular block two days after the procedure, during atrial tachycardia 2:1 atrioventricular conduction was present. After six months, however, 1:1 atrioventricular conduction was present during atrial tachycardia and repeat fulguration was necessary.

Accessory pathway conduction had been present since fulguration in one patient in whom atrio- ventricular conduction was maintained via an accessory atrioventricular pathway. In the other patient, who was in paced rhythm immediately after fulguration, accessory pathway conduction became apparent for the first time during the second month after the procedure.

It was not possible to assess conduction via the normal atrioventricular pathway from the surface electrocardiogram in the two patients with accessory pathway conduction, but, of the remaining 27 , five had evidence of atrioventricular conduction (group 1), 11 had complete atrioventricular block with a spontaneous ventricular rate $\geqslant \mathbf{4 0}$ beats/min (group 2), and 11 had complete atrioventricular block with a ventricular rate $<\mathbf{4 0}$ beats/min (group 3 ). The ratio of low right atrial to His bundle electrograms (A:H ratio) immediately before fulguration was greatest in group 1 and least in group 3; these differences did not reach statistical significance. In addition, there was no significant difference in the $\mathrm{HV}$ interval (time from His bundle electrogram to onset of ventricular depolarisation) before fulguration between the three groups.

Table 2 shows the response of spontaneous heart rhythm to exercise. During exercise seven patients with complete atrioventricular block demonstrated an increase in intrinsic ventricular rate. The patient with atrial flutter showed enhancement of atrioventricular conduction on exercise, whereas two patients with first degree atrioventricular block before exercise developed an increase in the degree of block. One of the patients with accessory pathway conduction demonstrated rate dependent accessory pathway block on exercise.

Table 3 shows the response of spontaneous heart rhythm to the Valsalva manoeuvre. Eight patients

Table 2 Spontaneous heart rhythm and its response to exercise in 28 patients after transvenous fulguration of atrioventricular conduction

\begin{tabular}{|c|c|c|c|c|c|}
\hline \multirow[b]{2}{*}{$\begin{array}{l}\text { Spontaneous } \\
\text { heart } \\
\text { rhythm }\end{array}$} & & \multicolumn{2}{|l|}{ Before exercise } & \multicolumn{2}{|l|}{ During exercise } \\
\hline & & Rhythm & $\begin{array}{l}\text { Ventricular } \\
\text { rate } \\
\text { (beats/min) }\end{array}$ & Rhythm & $\begin{array}{l}\text { Ventricular } \\
\text { rate } \\
\text { (beats/min) }\end{array}$ \\
\hline $\begin{array}{l}\text { Patients with A/V conduction } \\
(\mathbf{n}=5) \text { : }\end{array}$ & $\begin{array}{r}3 \\
11 \\
5 \\
2 \\
1 \\
1 \\
1 \\
1 \\
1\end{array}$ & $\begin{array}{l}\text { VVI pacing } \\
\text { VVI pacing } \\
\text { VVI pacing } \\
\text { CHB } \\
\text { S/R } \\
\text { S/R } 1^{\circ} \text { HB } \\
\text { S/R } 1^{\circ} \text { HB } \\
3: 2 \text { Wenckebach } \\
\text { A flutter, } 5: 1 \\
\text { A/V block }\end{array}$ & $\begin{array}{l}70 \\
60 \\
60 \\
\text { Mean } 48 \\
75 \\
74 \\
60 \\
\text { Mean } 84 \\
60\end{array}$ & $\begin{array}{l}\text { VVI pacing } \\
\text { VVI pacing } \\
\text { CHB } \\
\text { CHB } \\
\text { S/R } \\
2: 1 \text { A/V block } \\
\text { CHB } \\
\text { 3:2 Wenckebach } \\
\text { A flutter, 3:1 } \\
\text { A/V block }\end{array}$ & $\begin{array}{l}70 \\
60 \\
\text { Mean } 77 \\
\text { Mean } 58 \\
143 \\
77 \\
75 \\
\text { Mean } 120 \\
100\end{array}$ \\
\hline $\begin{array}{l}\text { S/R with AP conduction } \\
\quad(n=2):\end{array}$ & $\begin{array}{l}1 \\
1\end{array}$ & $\begin{array}{l}\mathbf{S} / \mathbf{R} \\
\mathbf{S} / \mathbf{R}\end{array}$ & $\begin{array}{l}79 \\
71\end{array}$ & $\begin{array}{l}\mathrm{S} / \mathrm{R} \\
2: 1 \mathrm{~A} / \mathrm{V} \text { block }\end{array}$ & $\begin{array}{l}158 \\
100\end{array}$ \\
\hline
\end{tabular}

See footnote to table 1 . AP, accessory pathway; $\mathrm{A} / \mathrm{V}$, atrioventricular. 
Table 3 Spontaneous heart rhythm and its response to the Valsalva manoeuvre in 29 patients after transvenous fulguration of atrioventricular conduction

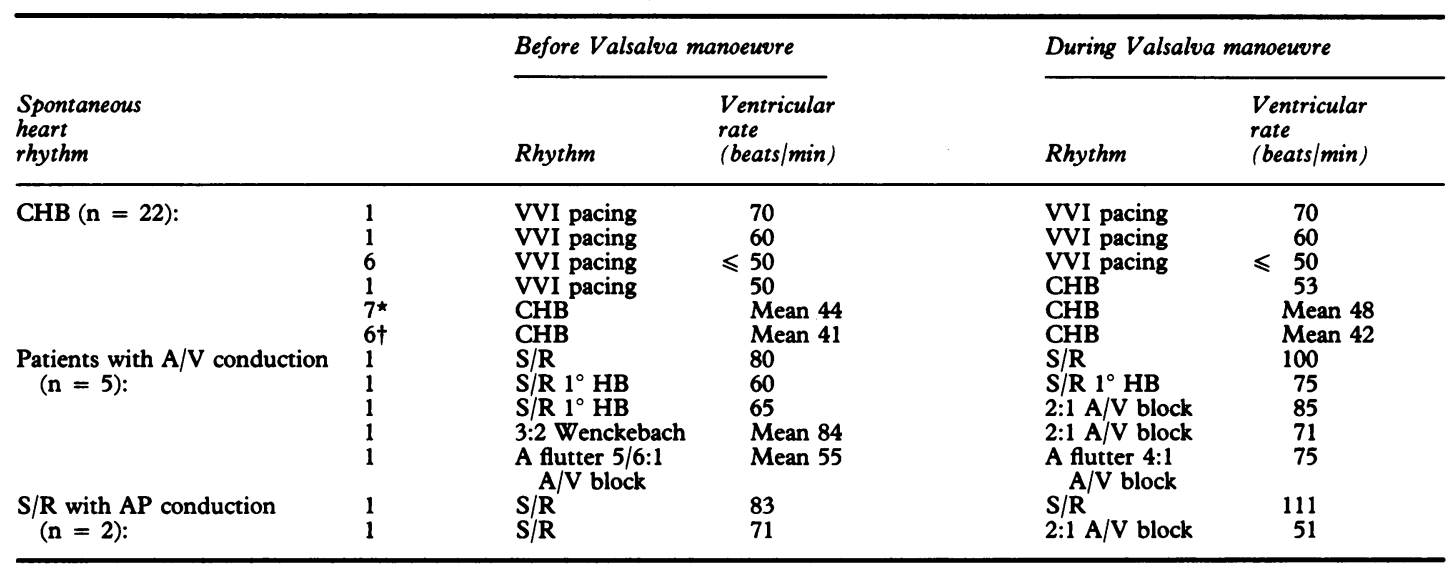

* Seven patients in whom R-R interval decreased by $>40 \mathrm{~ms}$ in response to Valsalva manoeuvre.

+ Six patients in whom $R-R$ interval decreased by $\leqslant \mathbf{4 0} \mathrm{ms}$ in response to Valsalva manoeuvre.

See footnotes to tables 1 and 2 .

with complete atrioventricular block demonstrated an increase in spontaneous ventricular rate ( $R-\mathbf{R}$ interval decreased by $>40 \mathrm{~ms}$ ) in response to the Valsalva manoeuvre. In a further six patients the $\mathrm{R}-\mathrm{R}$ interval did not decrease by $>40 \mathrm{~ms}$ and in this group the intrinsic ventricular rate before Valsalva was lower. Two patients developed a rate dependent increase in atrioventricular block, as did one patient with accessory pathway conduction, in response to Valsalva. The patient with atrial flutter demonstrated enhanced atrioventricular conduction.

During Holter monitoring at rest, with the pacemaker programmed to a low rate ventricular demand mode, seven patients demonstrated a variation in the degree of atrioventricular block, including one patient who showed both first degree and complete atrioventricular block.

\section{EXERCISE CAPACITY}

The 28 patients exercised during ventricular demand pacing at 60 or 70 beats/min demonstrated a decreased exercise capacity. Mean (SD) exercise time was $43(24) \%$ of the predicted value for their age and sex. ${ }^{5}$ The six patients with mitral valve disease had a lower exercise capacity $(37(25) \%$ ) than those without evidence of structural heart disease $(45(24) \%)$, though the difference was not statistically significant. The reason for termination of exercise was dyspnoea in 19 patients; dyspnoea and dizziness in three; dyspnoea and fatigue in three; and dizziness, fatigue, or intermittent claudication in the remainder. The 16 patients with rate responsive pacemakers demonstrated a significantly better but still impaired exercise capacity during "physiological" pacing $(63(25) \%)$ compared with their performance during constant rate pacing $(37(19) \%)$ $(\mathrm{p}<0.001)$ (fig 1$)$. There was no correlation between

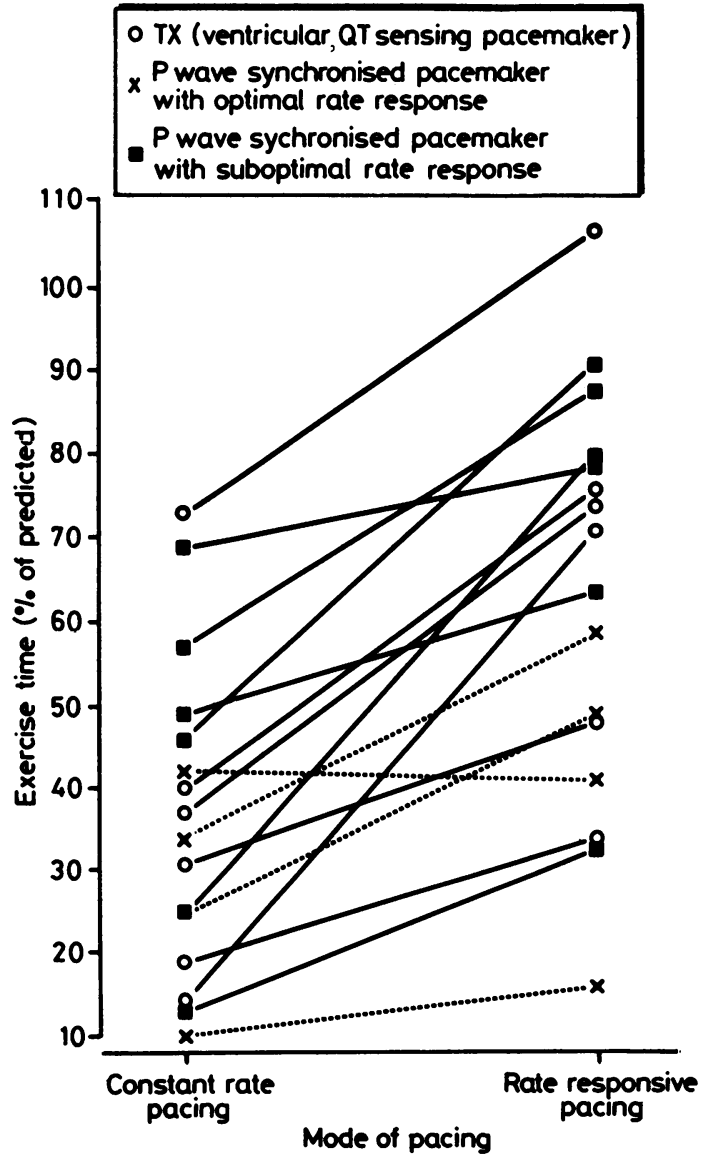

Fig 1 Exercise time (as \% of predicted) during constant rate and rate responsive pacing in 16 patients with "physiological" pacing systems. 
Table 4 Exercise capacity (mean (SD)) in constant rate ventricular demand and rate responsive modes in 16 patients with "physiological" pacing systems

\begin{tabular}{lll}
\hline & $\begin{array}{l}\text { Exercise capacity } \\
\text { (\%o of predicted) } \\
\text { during VVI pacing }\end{array}$ & $\begin{array}{l}\text { Exercise capacity } \\
\text { (\% of predicted }) \\
\text { during rate responsive } \\
\text { pacing }\end{array}$ \\
\hline $\begin{array}{l}\text { TX pacemaker } \\
(\mathrm{n}=6)\end{array}$ & $35 \cdot 7(20.9)$ & $68.3(25 \cdot 2)$ \\
$\begin{array}{l}\text { DDD with optimal } \\
\text { rate response } \\
(\mathrm{n}=4)\end{array}$ & $27.8(13 \cdot 7)$ & $41.4(18 \cdot 4)$ \\
$\begin{array}{l}\text { DDD/VAT with } \\
\text { suboptimal rate } \\
\text { response }(\mathrm{n}=6)\end{array}$ & $43.2(20 \cdot 7)$ & $72.5(21.5)$ \\
\hline
\end{tabular}

See footnote to table 1 .

exercise capacity during constant rate or "physiological" pacing and the mean (SD) maximum rise in any of three enzymes (creatine kinase 658 (793) IU/l, lactate dehydrogenase $777(689) \mathrm{IU} / 1$, and aspartate transaminase $115(196) \mathrm{IU} / \mathrm{l}$ ) after atrioventricular fulguration.

During exercise testing the six patients with $\mathrm{TX}$ (ventricular, QT sensing) pacemakers demonstrated an adequate rate response, the mean (SD) R-R interval decreasing from 823 (8) $\mathrm{ms}$ before exercise to 488 (70) ms at maximum exercise. Four of the 10 patients with dual chamber pacemaker systems showed an appropriate increase in ventricular rate during exercise (optimal rate response). The remaining six, however, reached the maximum ventricular rate response to sensed atrial activity before the point of termination of exercise and consequently the ventricular rate fell abruptly (suboptimal rate response). This fall in the ventricular rate is related to pacemaker blocking modes. Table 4 shows the exercise capacity of these 16 patients in constant rate ventricular demand and rate responsive modes. There was no significant difference in the degree of improvement during "physiological" pacing as compared with constant rate pacing between the three groups. Therefore, a suboptimal rate response did not appear to produce less improvement in exercise capacity during "physiological" pacing.

The most striking feature in these patients at review after transvenous atrioventricular fulguration was the frequency of exertional dyspnoea. Although all patients had been free of palpitation after the procedure, 13 patients had developed exertional dyspnoea and in two patients pre-existing dyspnoea has worsened. Two patients with mitral valve replacement and chronic atrial fibrillation who had had a rapid ventricular response (cases 27 and 28 ) had become less dyspnoeic after the procedure (table 5 ). Before atrioventricular fulguration none of the 22 patients without evidence of structural heart disease complained of exertional dyspnoea. Although 13 complained of breathlessness after the procedure, this was not related to the type of pacemaker implanted; of those who complained of exertional dyspnoea, four had constant rate and nine had rate responsive pacemakers, and of those who remained free of dyspnoea, three had constant rate and six had rate responsive pacemakers. Eleven patients who complained of exertional dyspnoea and four who did not had complete atrioventricular block at the time of this study (table 5).

The patients with exertional dyspnoea had a significantly shorter exercise time $(p<0.01)$ than the nine who remained symptom free when exercised in their usual pacing mode (fig 2). Only four patients had exercise tests before undergoing transvenous atrioventricular fulguration. In these patients exercise capacity during treadmill testing before and after fulguration corresponded with the presence or absence of exertional dyspnoea.

\section{Discussion}

Most patients with recurrent supraventricular tachycardia respond satisfactorily to antiarrhythmic drug treatment. Surgical intervention, for example localised atrial excision ${ }^{67}$ and ablation of an accessory pathway, ${ }^{89}$ has been used for a few patients who

Table 5 Presence of exertional dyspnoea before and after the procedure in 29 patients undergoing transvenous fulguration of atrioventricular conduction

\begin{tabular}{|c|c|c|c|c|c|}
\hline \multirow{2}{*}{$\begin{array}{l}\text { Exertional dyspnoea } \\
\text { before } \\
\text { fulguration }\end{array}$} & \multirow{2}{*}{$\begin{array}{l}\text { Exertional dyspnoea } \\
\text { after } \\
\text { fulguration }\end{array}$} & \multirow{2}{*}{$\begin{array}{l}\text { No of } \\
\text { patients }\end{array}$} & \multicolumn{3}{|c|}{ Spontaneous heart rhythm } \\
\hline & & & $C H B$ & $A / V$ conduction & $A P$ conduction \\
\hline $\begin{array}{l}\text { No } \\
\text { No } \\
\text { Yes } \\
\text { Yes } \\
\text { Yes }\end{array}$ & $\begin{array}{l}\text { No } \\
\text { Yes } \\
\text { Yes (same) } \\
\text { Yes (worse) } \\
\text { Yes (better) }\end{array}$ & $\begin{array}{c}9 \\
13 \\
3 \star \\
2 \dagger \\
2 \star\end{array}$ & $\begin{array}{r}4 \\
11 \\
3 \\
2 \\
2\end{array}$ & $\begin{array}{l}3 \\
2 \\
0 \\
0 \\
0\end{array}$ & $\begin{array}{l}2 \\
0 \\
0 \\
0 \\
0\end{array}$ \\
\hline
\end{tabular}

*Mitral valve replacement. †Mitral stenosis. See footnotes to tables 1 and 2. 


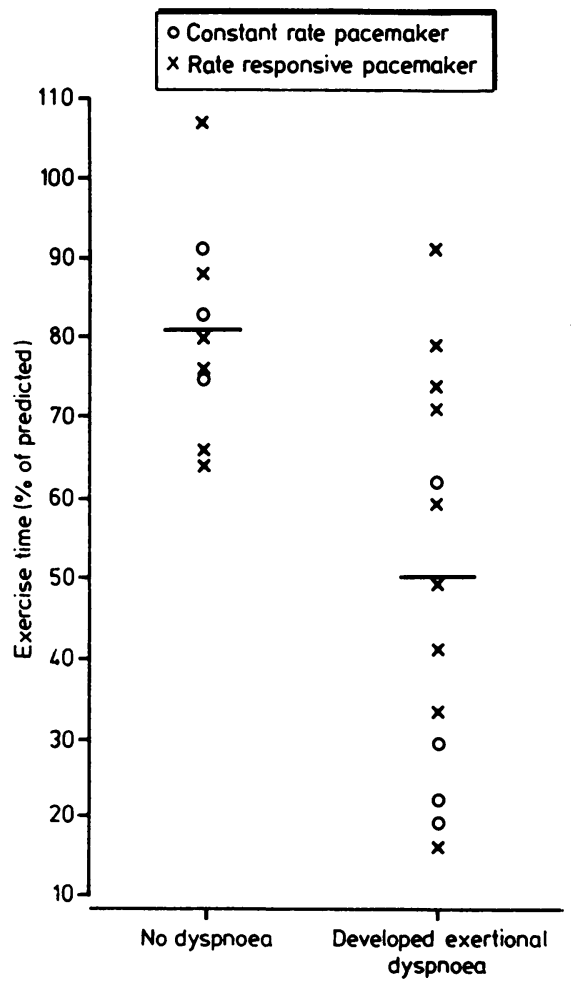

Fig 2 Exercise time (as \% of predicted) after atrioventricular fulguration of 22 patients without structural heart disease. Mean values are shown for the 13 who developed exertional dyspnoea and the nine who did not.

were refractory to or intolerant of such treatment. For most patients, however, the only surgical treatment that is appropriate is ablation of the atrioventricular node and His bundle. ${ }^{1011}$ Catheter techniques for producing atrioventricular block avoid open heart surgery. ${ }^{1-3}$ Although the technique has been reported to be safe and effective ${ }^{4}$ little has been reported about the long term results.

At follow up an average of 16 months after fulguration, $76 \%$ of patients in the current series had complete atrioventricular block. Similar results were reported in an earlier study ${ }^{4}(74 \%)$ and also after cryosurgical ablation of the atrioventricular node and $\mathrm{His}$ bundle $(77 \%) .{ }^{12}$ Repeat fulguration was necessary in $14 \%$ of patients because atrioventricular conduction had returned, usually within the first few days. In $10 \%$ of patients undergoing fulguration, however, atrioventricular conduction returned more than four weeks after the procedure, but there was no recovery of conduction after six months.
Gallagher $e$ al have suggested that the best results are obtained by ablating the proximal portion of the His bundle, ${ }^{1}$ which is identified by recording the longest possible HV interval associated with a large His bundle deflection and an atrial electrocardiogram $>0.25 \mathrm{mV}$. The $\mathrm{HV}$ interval immediately before fulguration in our series did not predict the long term result, and although patients with complete atrioventricular block and a low ventricular rate had the smallest $\mathrm{A}: \mathrm{H}$ ratio, the number of patients was too small to draw a definite conclusion. Persistent complete atrioventricular block is not essential for tachycardia control.

Our results suggest that the intrinsic ventricular pacemaker is influenced by autonomic nervous system activity in some patients. Of the patients with complete atrioventricular block, $33 \%$ demonstrated a reduction in cycle length of the intrinsic ventricular pacemaker with exercise and $36 \%$ in response to the Valsalva manoeuvre. The intravenous administration of atropine in previous studies was found to have no effect on the rate of the intrinsic ventricular pacemaker $^{212}$ and the implanted pacemaker was not inhibited by spontaneous ventricular activity during treadmill exercise testing, ${ }^{212}$ although only a few patients were studied. Klein et al showed that an isoprenaline infusion significantly increased the rate of the intrinsic ventricular pacemaker in a dose related manner after cryosurgical ablation of atrioventricular conduction. ${ }^{12}$ The mean cycle length of the spontaneous ventricular rhythm in our patients was $1555 \mathrm{~ms}$ (range $1140-2480 \mathrm{~ms}$ ), which resembles that reported for patients with intra-hisian block secondary to disease of the conduction system. ${ }^{1314}$ In some patients with persistent atrioventricular conduction there was a rate dependent increase in the degree of atrioventricular block in response to exercise and the Valsalva manoeuvre. The degree of atrioventricular block also varied in individual patients during several hours of rest, which implies that the spontaneous heart rhythm or escape interval observed at routine pacemaker clinic visits may not accurately reflect the state of the atrioventricular conducting system.

We were concerned that over $50 \%$ of our patients had developed exertional dyspnoea or had had worsening of pre-existing dyspnoea after atrioventricular fulguration. Exercise capacity during ventricular demand pacing was reduced to $43 \%$ of the predicted value for their age and sex. The 16 patients with rate responsive pacemakers demonstrated a significantly better but still impaired exercise capacity during "physiological" pacing as compared with their performance during constant rate pacing. Not all the patients in our study had an exercise test before fulguration. Increases in cardiac enzymes have been 
reported after catheter induced atrioventricular fulguration, ${ }^{124}$ although there was no other evidence of myocardial damage or important long term complications. Atrioventricular fulguration with an active fixation electrode and low energy shocks $(50 \mathrm{~J})$ has been attempted, ${ }^{15}$ but this also produced similar changes in creatine kinase concentrations. The cause of the impaired exercise capacity and exertional dyspnoea in our patients remains uncertain but possibilities include the presence of or progression of coexisting heart disease, the implantation of constant rate pacemakers, pacemaker malfunction, myocardial or valvar damage produced at the time of fulguration, and impairment of the sinus node response to physiological stimuli.

During constant rate ventricular pacing the exercise capacity of patients without evidence of structural heart disease was reduced to $45 \%$ of that predicted. Most of these patients had reentrant tachycardia and almost certainly will have had otherwise normal hearts before atrioventricular fulguration. Atrial synchronised ventricular pacing improves exercise performance in most patients in complete heart block more than constant rate ventricular pacing. ${ }^{1617}$ This improved work capacity is largely the result of the chronotropic response to exercise rather than the maintenance of the normal sequence of cardiac chamber activation. ${ }^{1819}$ Although $41 \%$ of our patients had constant rate ventricular demand pacemakers, the exercise time of those with rate responsive systems was reduced to $63 \%$ of that predicted during "physiological" pacing. We also found that the development of exertional dyspnoea after atrioventricular fulguration was not related to the type of pacemaker (constant rate or rate responsive) implanted. The group of patients with dual chamber pacing systems who demonstrated a suboptimal rate response during exercise had as impressive an improvement in exercise capacity during "physiological" pacing as patients with optimal dual chamber function and with appropriate TX function. In addition, we found no evidence of sinus node dysfunction in patients with dual chamber systems. It is therefore difficult to attribute the impaired exercise capacity in our patients to coexisting heart disease or limitations of pacemaker function. One possible explanation is that transvenous atrioventricular fulguration impairs right or left ventricular function or both. Surawicz suggested that the lesion produced by atrioventricular fulguration could be appropriately characterised as the equivalent of a small septal infarction ${ }^{20}$ and it seems likely that there is more extensive damage than a mere interruption of the His bundle.

The results of our study suggest that rate responsive rather than constant rate pacemakers should be implanted after atrioventricular fulguration, in contrast with the practice described in an early report. ${ }^{2}$ Even with "physiological" pacing, however, exercise capacity is likely to be impaired. Therefore, we believe that young patients with atrioventricular or atrioventricular nodal reentrant tachycardia should only be treated with transvenous atrioventricular fulguration when frequent distressing symptoms persist despite medical treatment and, where appropriate, antitachycardia pacing.

\section{References}

1 Gallagher JJ, Svenson RH, Kasell JH, et al. Catheter technique for closed-chest ablation of the atrioventricular conduction system: a therapeutic alternative for the treatment of refractory supraventricular tachycardia. N Engl f Med 1982;306:194-200.

2 Scheinman MM, Morady F, Hess DS, Gonzalez R. Catheter induced ablation of the atrioventricular junction to control refractory supraventricular arrhythmias. $\mathcal{F} A M A$ 1982;248:851-5.

3 Critelli G, Perticone F, Coltorti F, Monda V, Gallagher $\mathrm{J}$. Closed chest modification of atrioventricular conduction system in man for treatment of refractory supraventricular tachycardia. $\mathrm{Br}$ Heart $\mathcal{f}$ 1983; 49:544-9.

4 Nathan AW, Bennett DH, Ward DE, Bexton RS, Camm AJ. Catheter ablation of atrioventricular conduction. Lancet 1984;i:1280-4.

5 Bruce RA, Kusumi F, Hosmer D. Maximal oxygen intake and nomographic assessment of functional aerobic impairment in cardiovascular disease. $\mathrm{Am}$ Heart $\mathcal{f}$ 1973;85:546-62.

6 Gillette PC, Garson A, Cooley DA, McNamara DG. Definitive surgical treatment of atrial automatic ectopic focus tachycardias [Abstract]. Circulation 1981;64:IV-225.

7 Josephson ME, Spear JF, Harken AH, Horowitz LN, Dorio RJ. Surgical excision of automatic atrial tachycardia: anatomic and electrophysiologic correlates. Am Heart f 1982;104:1076-85.

8 Cobb FR, Blumenschein SD, Sealy WC, Boineau JP, Wagner GS, Wallace AG. Successful surgical interruption of the bundle of Kent in a patient with Wolff-Parkinson-White syndrome. Circulation 1968;38:1018-29.

9 Gallagher JJ, Sealy WC, Anderson RW, et al. Cryosurgical ablation of accessory atrioventricular connections: a method for correction of the pre-excitation syndrome. Circulation 1977;55:471-9.

10 Giannelli S, Ayres SM, Gomprecht RF, Conklin EF, Kennedy RJ. Therapeutic surgical division of the human conduction system. $\mathcal{F} A M A$ 1967;199:155-60.

11 Sealy WC, Gallagher JJ, Kasell JH. His bundle interruption for control of inappropriate ventricular responses to atrial arrhythmias. Ann Thorac Surg 
1981;32:429-38.

12 Klein GJ, Sealy WC, Pritchett EL, et al. Cryosurgical ablation of the atrioventricular node/His bundle: long-term follow-up and properties of the junctional pacemaker. Circulation 1980;61:8-15.

13 Narula OS, Narula JT. Junctional pacemakers in man. Response to overdrive suppression with and without parasympathetic blockade. Circulation 1978;57: 880-9.

14 Narula OS, Scherlag BJ, Javier RP, Hildner FJ, Samet $P$. Analysis of the A-V conduction defect in complete heart block utilizing His bundle electrograms. Circulation 1970;41:437-48.

15 Holt PM, Boyd EG, Crick JC, Sowton E. Low energies and helifix electrodes in the successful ablation of atrioventricular conduction. PACE 1985;8:639-45.

16 Kruse I, Rydén L. Comparison of physical work capacity and systolic time intervals with ventricular inhibited and atrial synchronous ventricular inhibited pacing. Br Heart $\mathcal{f}$ 1981;46:129-36.

17 Fananapazir L, Srinivas V, Bennett DH. Comparison of resting haemodynamic indices and exercise performance during atrial synchronized and asynchronous ventricular pacing. $P A C E$ 1983;6:202-9.

18 Karlof I. Haemodynamic effect of atrial triggered versus fixed rate pacing at rest and during exercise in complete heart block. Acta Med Scand 1975; 197:195-206.

19 Fananapazir L, Bennett DH, Monks P. Atrial synchronized ventricular pacing. Contribution of the chronotropic response to improved exercise performance. $P A C E$ 1983;6:601-8.

20 Surawicz B. A tactic of last resort. $N$ Engl $\mathcal{f}$ Med 1982;306:234-5. 